\title{
A Comprehensive Overview of Al-Enabled Music Classification and Its Influence in Games
}

\section{Tiancheng Yang ( $\square$ mfa2dh4@163.com )}

Yunnan Normal University

\section{Shah Nazir}

University of Swabi https://orcid.org/0000-0003-0126-9944

\section{Research Article}

Keywords: Music, Al, ML, intelligent devices, smart industry, Al-enable music

Posted Date: December 6th, 2021

DOI: https://doi.org/10.21203/rs.3.rs-1089338/v1

License: (c) (1) This work is licensed under a Creative Commons Attribution 4.0 International License. Read Full License

Version of Record: A version of this preprint was published at Soft Computing on January 22nd, 2022. See the published version at https://doi.org/10.1007/s00500-022-06734-4. 


\title{
A comprehensive overview of AI-enabled music classification and its influence in games
}

\author{
Tiancheng Yang ${ }^{1}$, Shah Nazir ${ }^{2}$ \\ ${ }^{1}$ School of music and dance, Yunnan Normal university, Kunming, Yunnan 650500, China \\ ${ }^{2}$ Department of Computer Science, University of Swabi, Swabi, Pakistan
}

\begin{abstract}
With the development and advancement of information technology, artificial intelligence (AI) and machine learning (ML) are applied in every sector of life. Among these applications, music is one of them which has gained attention in the last couple of years. The music industry is revolutionized with AIbased innovative and intelligent techniques. It is very convenient for composers to compose music of high quality using these technologies. Artificial intelligence and Music (AIM) is one of the emerging fields used to generate and manage sounds for different media like the Internet, games, etc. Sounds in the games are very effective and can be made more attractive by implementing AI approaches. The quality of sounds in the game directly impacts the productivity and experience of the player. With computer-assisted technologies, the game designers can create sounds for different scenarios or situations like horror and suspense and provide gamer information. The practical and productive audio of a game can guide visually impaired people during other events in the game. For the better creation and composition of music, good quality of knowledge about musicology is essential. Due to AIM, there are a lot of intelligent and interactive tools available for the efficiency and effective learning of music. The learners can be provided with a very reliable and interactive environment based on artificial intelligence. The current study has considered presenting a detailed overview of the literature available in the area of research. The study has demonstrated literature analysis from various perspectives, which will become evidence for researchers to devise novel solutions in the field.
\end{abstract}

Keywords: Music, AI, ML, intelligent devices, smart industry, AI-enable music.

\section{Introduction}

With the expansion and progression of IT, AI and ML are applied in every real-life field. Music is one of the applications which has achieved attention since the last couple of years. The industry of music is transformed with AI-based innovative and intelligent tools. AIM is one of the developing fields used to produce and accomplish sounds for diverse media like the Internet, games, etc. Various approaches were being presented in the area. Mantaras and Arocs [1] have analyzed three primarily implemented computer-based music systems with the techniques of AI. These systems are compositional, improvisational, and performance. The study focuses on the explanation of SAXEX, a computer-assisted 
platform that can be efficiently and effectively used to produce expression and music similar to that of human beings. The proposed system can only generate jazz ballads, but it can be easily modified to other kinds of music. There are various areas of computer-based music in which artificial intelligence is playing the role of backbone. Roads [2] has surveyed the four sections of music named composition, performance, music theory, and digital sound processing. The study explored the applications and implementation of AI-based intelligent and intelligent systems in the world of music. With these intelligent techniques, the computer-based music frameworks can be significantly improved and changed positively. Due to the advancement in AI and information technology, the computer system can perform different activities based on music very efficiently.

Frid et al. [3] have developed a system based on AI to take the song as input from the user and then redevelop that song based on AI algorithm. The proposed approach has a user-friendly interface, and the user can interact with it very efficiently. The system will benefit the video makers who want to integrate suitable and healthy music with the video. To evaluate the performance of the system, it was tested with about 104 video editors. Then they found it very effective for the communication between humans and AI grounded intelligent systems. Sturm et al. [4] have proposed a study on the impacts of AI-based music systems on copyright issues and job seekers in the music industry. The study shows that AI-based music will affect the copyright laws and will cause trouble to it. There will be a problem with the possession of the musical contents generated by the intelligent systems, and it is possible that they are practiced and taught the illegal contents. The advancement and improvements in AI-based music platforms show that these intelligent systems will replace humans in the industry. Lopez-Rincon et al. [5] have presented a study on the various AI-based techniques for music composition on different algorithms. With the implementation of applications of various artificial intelligence methodologies, the algorithmic music composition is generated. Different artificial frameworks like decision trees, neural networks, generative models, and many more are used for effective music composition. The study analyzed other AI grounded intelligent models in the previous seven years for the generation of music. The use of AI-based music generation is an emerging field of artificial intelligence.

Louie et al. [6] have suggested artificial intelligence grounded intelligent system which allows the users to generate the music according to their comfort. With the system's deployment, the user will be able to create the sound of a specific voice along with different expressions like unhappy, joyful, and astonished. The system was evaluated, and it was found that it is capable of improving the trust and experience of users while working with intelligent music systems based on the techniques and methodologies of artificial intelligence. Moreover, the system has reduced the issue of making the users frustrated with the composition of music by AI-based system. Tan and Li [7] have put forward a study on the development and implementation of artificial intelligence-based techniques for the generation of music. The study 
discusses the basics of music along with different deep learning methodologies for the composition of music. The performance and other styles of music based on AI were also addressed in the proposed study. The design of music with the lamentation of various AI techniques is a valuable and novel aspect of artificial intelligence and the music industry. Due to deep learning, the usage of AI in the composition of music is increasing rapidly and efficiently.

The current study has considered presenting a detailed overview of the literature available in the area of research. Instead, the study has demonstrated literature analysis from various perspectives, which will become evidence for researchers to devise novel solutions in the field.

\section{Composing music by intelligent devices}

The music industry is facilitated with advanced and intelligent devices. Qiu et al. [8] have presented a system based on the valence-arousal model to generate music using artificial intelligence. The user has to input the emoji in the design, and based on the intelligent and intelligent techniques, and the system will create music based on the emoji. The system has a very interactive interface, and the user can use communication very efficiently and effectively. With such a kind of platform, everyone will compose the music according to his comfort and situation. The proposed system is the integration of different technologies like AI, NLP, and human-computer interaction. Zulic [9] has presented a study to give an overview of the literature on the implementation of artificial intelligence in the generation, composition, and the learning of music. In today's modern world, AI-based technologies are everywhere, and the same is valid for music. To study the applications of AI in composition, the author has taken AIVA as an example. It is one of the first music composers based on artificial intelligence. To take a look at the performance, the study focuses on controlling the piano with different body gestures by the world's best dancer Kaiji Moriyama. Camurri [10] has performed a survey of the recent development and enhancement in one of the unexplored areas of AI called artificial intelligence and music(AIM). The study explores some of the factors of artificial intelligence, which can significantly improve the existing AI-based music generation work. According to the survey, AIM is not just about implementing AI grounded techniques to the music, but both AI and music have positive impacts on one another. Different concepts related to intelligence can be expressed with music. To solve other issues in the musical procedures, various formalisms, and hybrid systems can be beneficial.

Malgaonkar et al. [11] have developed a system to generate music by implementing an intelligent procedure. The system is creating different musical sounds by using already fitted knowledge of music like chord and scale patterns. The proposed system will select the suitable and efficient note and produce it using an automatic process. In the overall working of the system, the music is composed of an innovative and intelligent algorithm. Making the computer-assisted system capable of managing the 
suitable theme is a challenging and hot topic for artificial intelligence and music practitioners. With the smart algorithm, the user will not recognize between man-made and computer-based music. Pandian [12] has proposed an intelligent system to evaluate and examine a person's sleeping pattern with the deployment of AI and therapy grounded on music to enhance the interval of sleeping along with dropping the stress level of a person. After the data about sleep is collected, it is given to the music platform. The platform is turning on and off based on recorded data to make the time of the rest of a person very efficient and productive. The proposed system can be implemented at every place and according to the comfort of the user. Dannenberg [13] has presented a study to show the applications of machine learningbased intelligent systems in the development and improvement of the music industry. With the implementation of intelligent and intelligent techniques based on artificial intelligence, various music instruments can be trained efficiently and effectively. These techniques have reduced a lot of workload from the composers, listeners, and singers. Due to the integration of AI and music, there is now very interactive communication possible between intelligent systems and musicians.

Dannenberg [14] has proposed a study on the efficient representation of music with the help of computerassisted technology. It is challenging to represent music manually as it changes with every single composition. With the use of computer-based applications, one can represent music in a very convenient and reliable way. Due to these applications, we can now proficiently represent dynamic and responsive composition. These faithful representations guarantee better communication between computers and humans. The computer applications allow us to understand the theory of music better. Fox and Khan [15] have presented a thoughtful and intelligent MAGMA system to generate music based on the three AIbased algorithms. The proposed system takes the song as an input from the user, and it creates music based on the structure of that song. The system is beneficial in the composition of a different kinds of music. With the integration of three AI-based intelligent algorithms, the system can produce a good quality of music. Other AI-based wise and smart applications have been used to tackle many hurdles and issues in music. Kumar et al. [16] have suggested architecture to make intelligent and intelligent AIbased systems more creative and constructive. The study has thoroughly analyzed one of the main areas of human-based creativeness named music. Various machines for the generation and composition of music have been studied. The proposed work gives an overview of the benefits, issues, and working of AI-based machines in the music industry. A practical and reliable system has been put forward to make AI-based intelligent systems very creative. The study has positive impacts on the usage and implementation of machines for one of the most incredible creative of humans called music.

Neeman [17] has proposed a study to study the connection between art and science. The work focuses on the generation of high-quality art with the deployment of AI-based intelligent architecture. Two efficient methodologies have been discussed to create poetry and music based on artificial intelligence. The first 
method follows the statistical approach to provide a convenient way of mechanical components of music. New music is generated from the already existing one, which will be similar to the old one. The other technique uses the integration of dialectal vocabulary and semantic figures to create poetry of good quality. Lupker and Turkel [18] have put forward a study to analyze the efficient working of AI grounded intelligent musical algorithms on big data based on music. The study shows a profound and practical connection between data about music and these intelligence algorithms. It was revealed that the performance and effectiveness of mode and key prediction algorithms can be enhanced by implementing various methodologies based on music theory. Due to the benefits of AI in music, different intelligent algorithms can now learn from the big data about music. The experts of the music sector can fully understand them. Kazi and Bhatia [19] have presented a system to generate good quality monophonic melodies based on the different methodologies like Elman Recurrent Neural Networks and two others. There are a lot of tasks performed while developing a single piece of music, but the melody is one of the most important and valuable features of that piece. The proposed architecture is based on two of the essential concepts of artificial intelligence called neural networks and genetic algorithms. The neural part learns from the provided sample while the genetic algorithm generates the melody based on the learned data of neural networks. Gueret et al. [20] have proposed an architecture to produce a high quality of music while working with AI-based intelligent ants on the graph. The corners of the graph are treated like notes, and the edges are like alterations from one note to another. The proposed system was tested with various devices, and the results were encouraging and efficient. With the secretion of pheromones by the ants on the edges, a nice and pleasant melody is produced. The system is based on the ant algorithm and AI-based intelligent methodologies.

\section{Efficient audio means a successful Game.}

Peerdeman [21] has presented a study to give an overview of the applications of audio music in the video game sector. With the advancement in information technology, people can now listen to music very innovatively while playing a game. The study focuses on the increasing demand and value of audio in video games. In the opinion of the people, the audio of a game is a very important factor for the success of that game. Due to the increased processing speed of the video games systems, the game audio processor can now provide very productive and efficient facilities to the player of the video games. Collins [22] has performed a survey on implementing and developing procedural music methodologies in video games. The study also identifies the dissimilarity between transformational and generative processes and the factors responsible for implementing these methodologies in video games. Some of the reasons for not using procedural music in games have been discussed as well as the upcoming advancements in this field are suggested. The integration of music with video games increases games' 
attractiveness, and people are getting addicted to it. Linek et al. [23] have proposed a study to show the impacts of background music on the learning process in education-based games. Music plays a precious part in encouraging students to learn through games. In the perception of games experts, background music is one of the main essential components of game designing and development. The study results show that music has an excellent convincing power to learn through games. Also, the background music in the educational games does not provide any hurdle in learning. Plut and Pasquier [24] have presented a study on the implementation of adaptive music in games for the better experience of the players. One of the attractive and valuable factors of video games is the integration of music in them. The study applies empirical research to find out various impacts of adaptive music in games. The analysis of the results shows that almost all the players pay great attention to the music of a particular game and are highly motivated by it. The study revealed that they are in favor of adaptive music instead of linear.

Plut and Pasquier [25] have performed a study to analyze and evaluate the performance and potential of adaptive music systems in video games. It allows us to make the generation of music for video games one step forward by implementing intelligent and intelligent algorithms and artificial intelligence. One of the standard features in all video games is music. Implementing generative methodologies and generating music is emerging as an essential and highly used phenomenon in video games. We can get many different types of music by adaptive learning very conveniently. Ahmed [26] has presented a study to determine what scope music can be included in the rules of a game. As in the movies, music plays a unique role in the narration it. The same is true for video games. The study suggested that it is not necessary or requirement that the music of all video games must be both ludic and narrative. The ludic theme of a video game is deeply analyzed for three different scenarios: guide, obstacle, and reward. In some games like karaoke, the music can play the role of a block and a reward. Gungormusler et al. [27] have proposed a system for the generation of good quality music and better interactive applications named barelyMusician. The system provides the listeners with innovative and pleasant music. The proposed approach works with the already existing music samples and creates a new one from the breakdown of these samples in real-time. In the area of entertainment, aural feedback is a precious factor. The system is tested and assessed with the audience, and they found it very effective and efficient for generating high-quality music.

Grimshaw et al. [28] have developed a study to determine the importance and applications of music in the gaming industry. With the advancement in information technology, the integration of music in games is considered an essential component. The deployment of sound in games is described in the perception of players of the game. The quality of music in the game can directly affect the experience and interaction of a player with the game. The impacts of usage of sound on the abilities of players of a game have been discussed. Tan et al. [29] have proposed a study to show the relationship between music and a player's 
performance while playing a game. The study followed an empirical approach with 20 respondents playing games- The Legend of Zelda and Twilight Princess for about forty-five minutes. The participants were subjected to play the games both with sound effects and without them. It was revealed that players' performance is directly affected by the presence of sound in the game. Without any sound, the performance was weakest. Karageorghis et al. [30] have put forward a study to find out the connection between music and the preparation for a good version of the soccer player. The data is collected in the form of interviews and questionnaires from about 34 soccer players, and it was analyzed. The results show that the music has a great effect on the players' skills and acts as stimuli for the emotions. The study also shows that the psychological health of the player is also affected by the music. This work is beneficial for the soccer player in the selection of suitable music.

\section{Digitalization and music}

Avdeeff [31] has performed a survey of the first album based on integrating human interference and artificial intelligence. With the release of Hello World, people can believe in implementing AI-based intelligent systems in their daily lives. The deployment of $\mathrm{AI}$ in music has made possible the generation of unique and pleasant music. The quick and convenient working of AI-based intelligent and intelligent systems made them the ultimate choice to be included in the generation and composing of music. Waldner [32] has proposed a study on the efficient marketing strategy for distributing music to the listeners. A novel and practical marketing framework is required to enhance music consumption on different platforms like smartphones and the Internet as one of the best marketing tools. The gaming industry is very thriving in reaching out to customers based on its business strategy compared to the music industry. The proposed study implemented the same business plan for the music distribution for efficient usage to the listeners. The current work has taken the UK music-technology RjDj as an example. Scott [33] has presented a study on the qualities and abilities required to generate better music for a game. The study discusses that the composer should be aware of both the music and technological developments in information technology. They should be able to recognize the working and integration of various components in the game engine. The study provided an overview of other valuable and novel developments in the field of the gaming industry for the composers of music. With advancement and improvements in technology, the music factor of the games will be changed in a very effective and positive manner. Rietveld et al. [34] have performed a survey on the deployment and collaboration of music in video games. The people related to the gaming sector believe that music is one of the main components of every video game. Different conferences are held around the globe to improve the effectiveness and efficiency of music in games. The integration of sound in games is now developing as a 
proper subject in the studies of games. The study suggests that the combination of music and fun is designed a lot, and it will be advancing much more in the upcoming times.

Arditi [35] has proposed a study that music can be found everywhere very quickly and efficiently in today's technological and digitalized world. People do not need to buy tapes and CDs, but they are now able to access different styles of music in no time. It does not mean that music is free, but listening to music through smartphones, cables, and playing games charges handsome money. The availability of music on every platform is made possible by developing and deploying modern and intelligent techniques. Sitonio and Nucciarelli [36] have developed a study to determine the impact of blockchain technology on the music sector while considering the effect on artists by the developing technology. Due to advanced applications like Apple Music, the listeners are now provided with particular music in no time. Still, these technologies are acting as a barrier between the artist and the audience. With the implementation of blockchain, this wall will be reduced, and the artist will be able to get the best profit from its generated product. The study also describes the undergoing developments and advancements that are taking place in the industry of music. Le et al. [37] have proposed a study on the importance and high value of music-based games in the opinion of gaming players. Entertainment in today's time is one of the primary and valuable needs. By analyzing the gaming industry in Vietnam, it was realized that it is developing and improving very rapidly and productively. With the development of smartphones, the craze for different games has been dramatically increased. A new music competition-based games are a very peaceful and polite source of enjoyment and attract gamers very easily.

Newcomb [38] has performed a study to show video game music as the type of separate musical genre. The study provides an overview of the transformation of video game music from the start to becoming a musical genre. In this technological time, video game is now available in different formats and styles. Due to the advancement in information and communication technology, video game music is still developing and entertaining people of various backgrounds and ethnicities. Therefore, the video game music genre has very healthy and productive impacts on modern society. Plans and Morelli [39] have conducted a study for innovative and efficient methods for the generation of music based on the experience-driven procedural process. Due to the advancement and development in the video games industry, composers must make music of high standard. The old-fashioned music of video games is very repetitive and boring, which cannot be applied to the nonlinear games of this modern time. The music in today's game is fascinating and adaptive according to the different events in the game. Aska [40] has presented a study to discuss the other music parameters required for designing and developing interactive media platforms as video games are nonlinear compared to movies. Hence, the interactivity and continuous sound apply only to video games for the music. Adaptive music is one of the primary factors of almost all video games. It undergoes different variations according to the changes in the activities of 
the player of a game. In today's society, adaptive music is taking the place of reactive music because of the emerging efficient and reliable game engines and sound methodologies.

\section{Artificial Intelligence and Musicology}

Ghildiyal and Sharma [41] have studied the efficient and effective taxonomy of music based on genre. Due to the development in the music sector and the profession of music, there are a number of the genre created and developed. It is an important task to separate them from one another and provide the listener with their choice. Different AI-based innovative and intelligent techniques have been applied for the classification of music. The proposed study have used AI-based innovative models and data filtering method on the dataset of GTZAN to resolve the hurdles in the type of music genre. Hou [42] has proposed a study on artificial intelligence applications in the teaching and learning of music education. The study focuses on the integration of AI-based innovative and intelligent techniques and music education. Data is collected from the students of different universities with the help of a questionnaire. The analysis shows that almost all the students favor implementing intelligent applications in the learning of music. According to the opinion of about 88.1 percent of students, the deployment of AI has made the interaction between teacher and student very effective and improved students' performance. The findings of the study suggest that ME should be innovated with the applications of artificial intelligence. Yuan [43] has conducted a survey on the importance of teaching the subject of artificial intelligence to students of music education. Artificial intelligence is developed a lot and is applied everywhere in everyday lives. It can be used very efficiently for the learning and generating of good music. The study suggests that it is very beneficial to teach the Music and AI course in music education. AI has revolutionized every aspect of human life, and the same is true for the music industry. It has provided a lot of benefits in generating as well as composing music.

Zhang and Wan [44] have performed a study to show the positive impacts of AI on music education in China based on the findings of existing work done in AI and music education. The intelligent applications of AI have changed the old-fashioned methods of music teaching into efficient and interactive techniques. Music institutions have to use artificial intelligence's philosophical and wise technological aspects in education for a better and effective learning environment. These techniques are very beneficial for efficient teaching and learning of music in China.

Yang [45] has presented a study to resolve the issues and hurdles in the existing traditional teaching of music education. The study applied artificial intelligence grounded effective methods to the teaching and learning of music. The proposed methodology was evaluated to check its performance. The findings suggest that intelligent methods can significantly improve traditional teaching methods and help students better understand. It was also that the implementation of AI-based techniques is beneficial in the 
innovation and development of music education. Nicholls et al. [46] have proposed a study on the composition and generation of music using AI-based intelligent and intelligent applications. With the deployment of these applications, the music industry is continuously on its way towards development and innovations. With the help of the participation of the songwriters, a computer-assisted intelligent machine can train very conveniently and efficiently. The system will perform the function of composing and producing the music. The usage of these smart devices in the music industry is one of the main advantages of information and communication technology innovations. Birtchnell [47] has developed an innovative and intelligent system for efficient and effective working with audio mastering engineers. The proposed approach is based on artificial intelligence, big data, and smart algorithms. It is capable of helping the audio mastering engineers in their daily workload. The system will coordinate with the music experts and will make their daily work routine very comfortable and peaceful. The developed architecture is a human-oriented system, and instead of taking the place of humans, it will perform its functions under the supervision of human audio experts.

Stere and Trausan-Matu [48] have proposed a study to generate music through a software-based system by providing the poem in written form. The proposed architecture looks for rhythms and emotions in the provided written text and computes it. After a thorough analysis of the poem, the system generates musical notes related to it. The study utilizes the process of sonification for the creating of melody based on provided non-speech audio. The music produced by the software is according to the mood as presented by the written poem given to the system. Zhang and Yang [49] have performed a study on the effectiveness of artificial intelligence in music education. AI-based systems are changing our lives, and the same is valid for music teaching and learning. The study focuses on the usage of artificial intelligence for the efficient working of musical instruction systems. The performance of the learners is assessed by collecting data through audio, video. The data analysis shows that the integration of intelligent techniques in music has changed the way of teaching and learning music. With the help of artificial intelligence, intelligent and intelligent music architectures have been designed and developed. Hebert et al. [50] have developed a study on the effects of music present in video games on the player's level of anxiety and stress. The study struggles to find out the connection between music in games and the stress level of the gamer. For the assessment, the game is played both in silence and in the musical atmosphere. The experimental results show that the cortisol is increased at a high rate in a game with background music enabled compared to the one played in the silent mood. Cortisol shows the stress level of the player. It is evident from the study that the sounds in the game cause the high-stress level.

\section{Analysis of the existing literature based on various libraries}


The current study has considered various libraries, including ScienceDirect, ACM, IEEE, and MDPI, for the search process of the proposed study. The purpose of the study was to identify mostly associated materials concerning the proposed study. The keywords ("AI-enabled") AND ("music") AND ("classification") AND ("game") were considered as the search items of the study. A number of research papers were identified associated with the area of research. The method/approach used is given in table 1 .

Table 1. Method/approach used for music

\begin{tabular}{|c|c|c|}
\hline $\begin{array}{l}\text { Reference } \\
\text { No. }\end{array}$ & Method/approach & Year \\
\hline$[1]$ & AI and music & 2002 \\
\hline [2] & music and $\mathrm{AI}$ & 1985 \\
\hline [3] & Music creation by example & 2020 \\
\hline [4] & $\begin{array}{l}\text { AI and music: open questions of copyright law and } \\
\text { engineering praxis }\end{array}$ & 2019 \\
\hline [5] & Amusic composition based on AI & 2018 \\
\hline [6] & Novice-AI music co-creation & 2020 \\
\hline [7] & A Tutorial on AI Music Composition & 2021 \\
\hline [8] & Mind Band & 2019 \\
\hline [9] & AI can change/improve/influence music & 2019 \\
\hline$[10]$ & On the role of artificial intelligence in music research & 1990 \\
\hline$[11]$ & AI-based intelligent music & 2013 \\
\hline$[12]$ & $\begin{array}{l}\text { Sleep pattern analysis and improvement by } \mathrm{AI} \text { and music } \\
\text { therapy }\end{array}$ & 2019 \\
\hline [13] & AI, ML, and music & 2000 \\
\hline$[14]$ & Music representation & 1993 \\
\hline [15] & AI to music composition & 2013 \\
\hline$[16]$ & Music composition using AI & 2020 \\
\hline$[17]$ & Arts, computers, and AI & 1996 \\
\hline [18] & $\begin{array}{l}\text { Music theory, the missing link between music-related big } \\
\text { data and AI }\end{array}$ & 2021 \\
\hline [19] & AI approaches for automated melody generation & 2013 \\
\hline$[20]$ & Ants can play music & 2004 \\
\hline
\end{tabular}




\begin{tabular}{|l|l|l|}
\hline$[21]$ & Sound and music in games & 2010 \\
\hline$[22]$ & procedural music in video games & 2009 \\
\hline$[23]$ & music in educational games & 2011 \\
\hline$[24]$ & music matters & 2019 \\
\hline$[25]$ & Generative music in video games & 2020 \\
\hline$[26]$ & Flipped learning as a new educational paradigm & 2016 \\
\hline$[27]$ & barelymusician & 2015 \\
\hline$[28]$ & Playing with sound & 2013 \\
\hline$[29]$ & $\begin{array}{l}\text { Effects of built-in audio versus unrelated background } \\
\text { music }\end{array}$ & 2010 \\
\hline$[30]$ & grounded theory of music use & 2018 \\
\hline$[31]$ & AI \& popular music & 2019 \\
\hline$[32]$ & Cross-industry innovation & 2011 \\
\hline$[33]$ & Music to middleware & 2014 \\
\hline$[34]$ & Hear the music, play the Game & 2017 \\
\hline$[35]$ & Music Everywhere & 2019 \\
\hline$[36]$ & blockchain on the music industry & 2018 \\
\hline$[37]$ & Music arena game & 2015 \\
\hline$[38]$ & video game music genre & 2012 \\
\hline$[39]$ & procedural music generation for games & 2012 \\
\hline$[40]$ & video game music & 2017 \\
\hline$[41]$ & Music genre classification & 2019 \\
\hline$[42]$ & $\begin{array}{l}\text { Practice and promotion strategy of college music } \\
\text { education }\end{array}$ & 2020 \\
\hline$[43]$ & Musical AI in music education & 2018 \\
\hline$[44]$ & Application of AI in music education & 2018 \\
\hline$[45]$ & AI in music education & 2017 \\
\hline$[46]$ & Collaborative AI in music production & \\
\hline$[47]$ & AI in audio mastering & 2010 \\
\hline
\end{tabular}




\begin{tabular}{|c|c|c|}
\hline [48] & musical accompaniment for a poem & 2017 \\
\hline [49] & Music assisted teaching system based on AI & 2021 \\
\hline$[50]$ & Physiological stress response to video-game playing & 2005 \\
\hline [51] & Changes of game music & 2012 \\
\hline$[52]$ & Detecting emotion in music & 2003 \\
\hline [53] & Saarland music data & 2011 \\
\hline [54] & Tangible distributed computer music for youth & 2017 \\
\hline [55] & Teaching the musical art for visually-impaired people & 2018 \\
\hline$[56]$ & Genetic music compositor & 1999 \\
\hline [57] & Algorithmic composition of popular music & 2012 \\
\hline [58] & Music recommender system & 2019 \\
\hline [59] & Personalized music recommendation & 2013 \\
\hline [60] & Cannibalizing or complementing? & 2016 \\
\hline [61] & music variation on genome platform & 2017 \\
\hline [62] & music notepad & 1998 \\
\hline [63] & computer recognition of solo piano music & 2000 \\
\hline [64] & Adaptive music & 2009 \\
\hline [65] & music for inducing emotive response & 2010 \\
\hline [66] & Designing sound-based computer games & 2003 \\
\hline [67] & Meaningful noise & 2005 \\
\hline [68] & Audio interaction in computer-mediated games & 2008 \\
\hline [69] & Listening to fear & 2011 \\
\hline$[70]$ & Left in the dark & 2008 \\
\hline [71] & The informative sound design in video games & 2013 \\
\hline [72] & audio in computer games & 2013 \\
\hline [73] & Role of audio in games & 2017 \\
\hline
\end{tabular}

The article type, publication title, subject areas, along publications in the ScienceDirect library are shown in figure 1. 


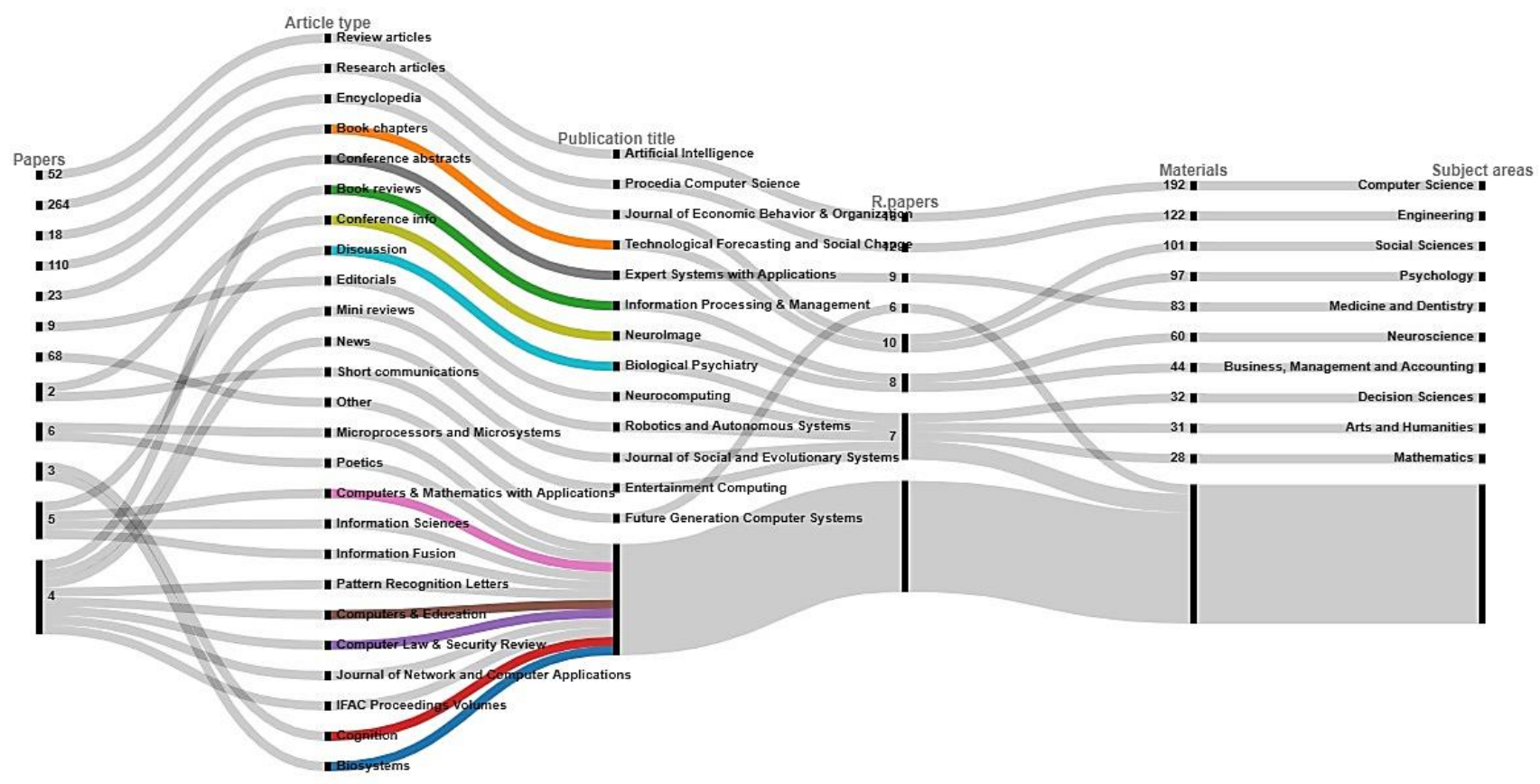

Figure 1. Article type, publication title, subject areas along with publications

The year-wise publications and the total number of papers are shown in figure 2.

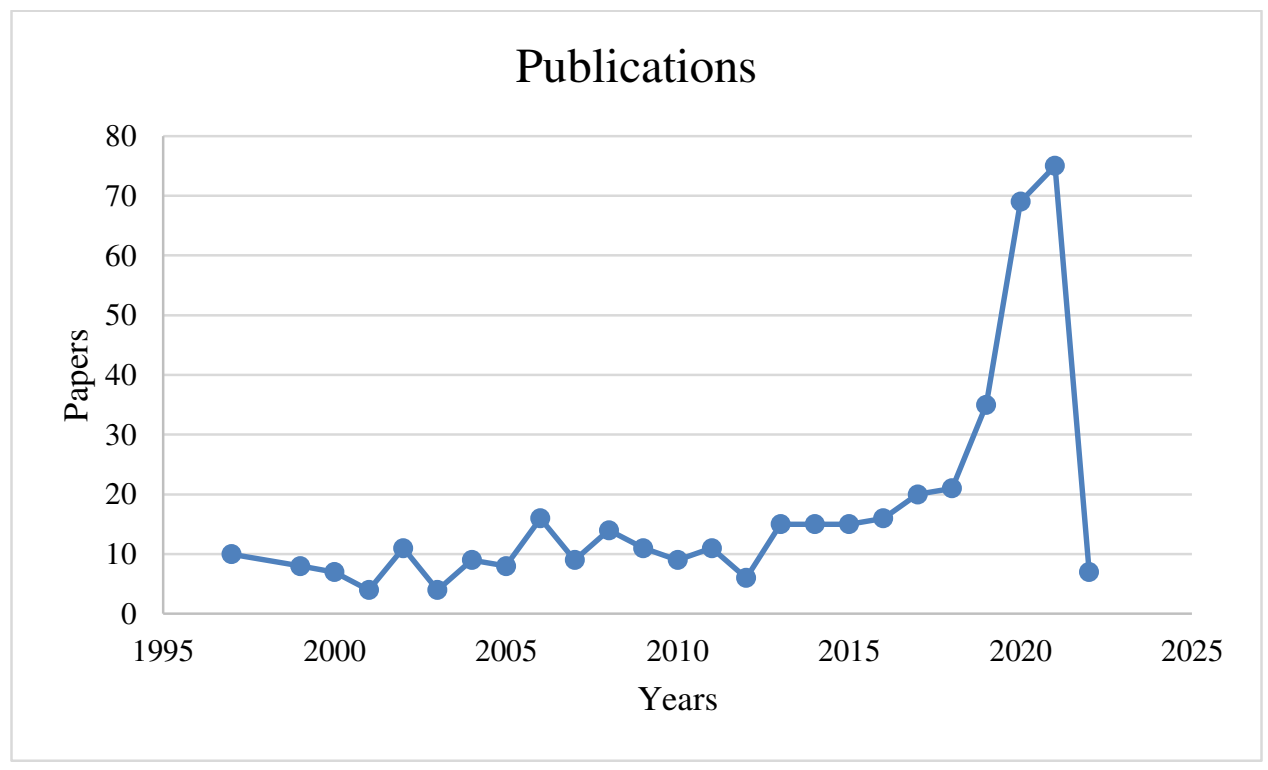

Figure 2. Year-wise publications

The conference sponsors and conference events with publications in the ACM library are shown in figure 3. 


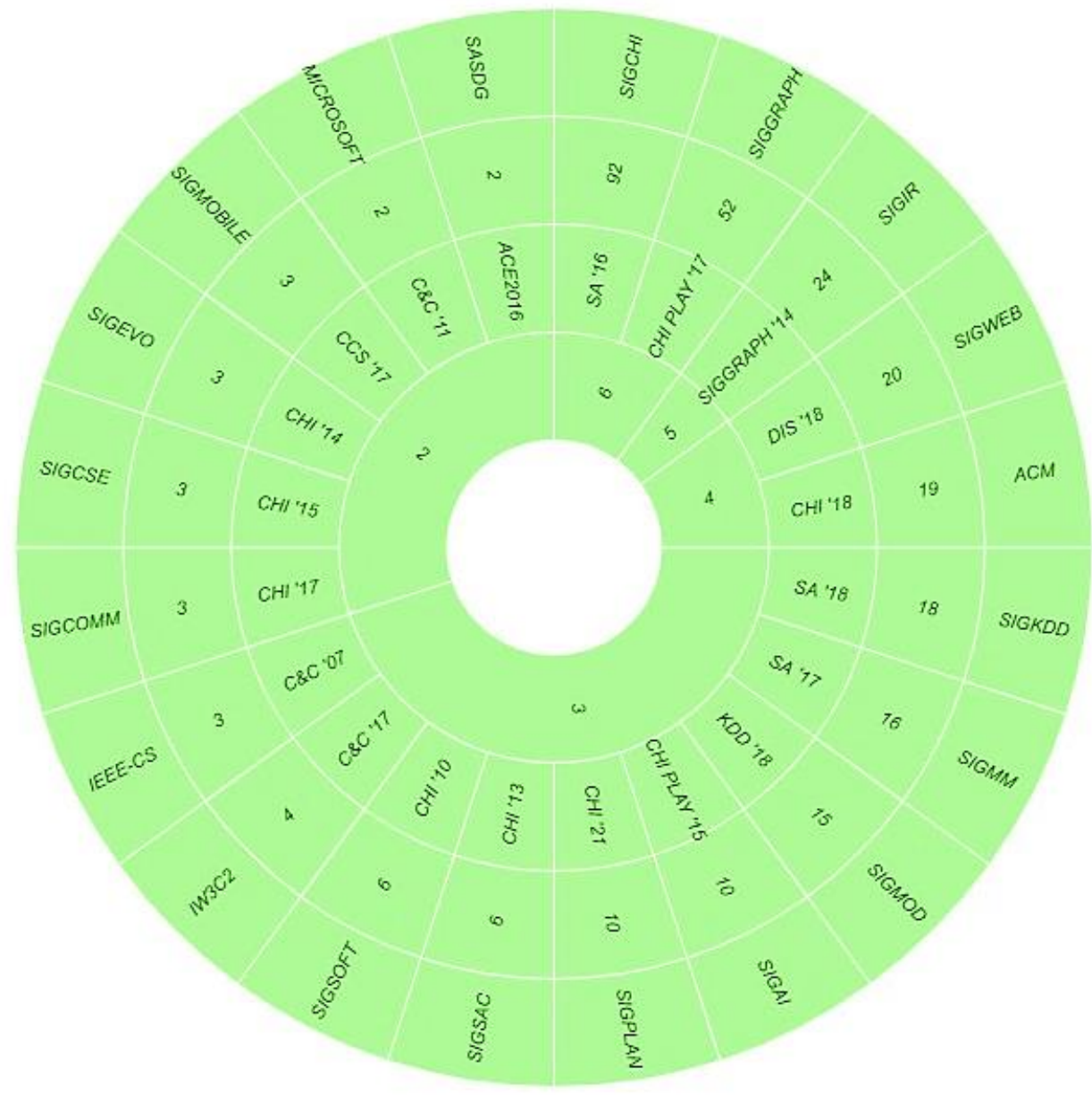

Figure 3. Conference events, conference sponsors with publications

Figure 4 briefly shows the publishers, media format, content types with publications in the mentioned library. 


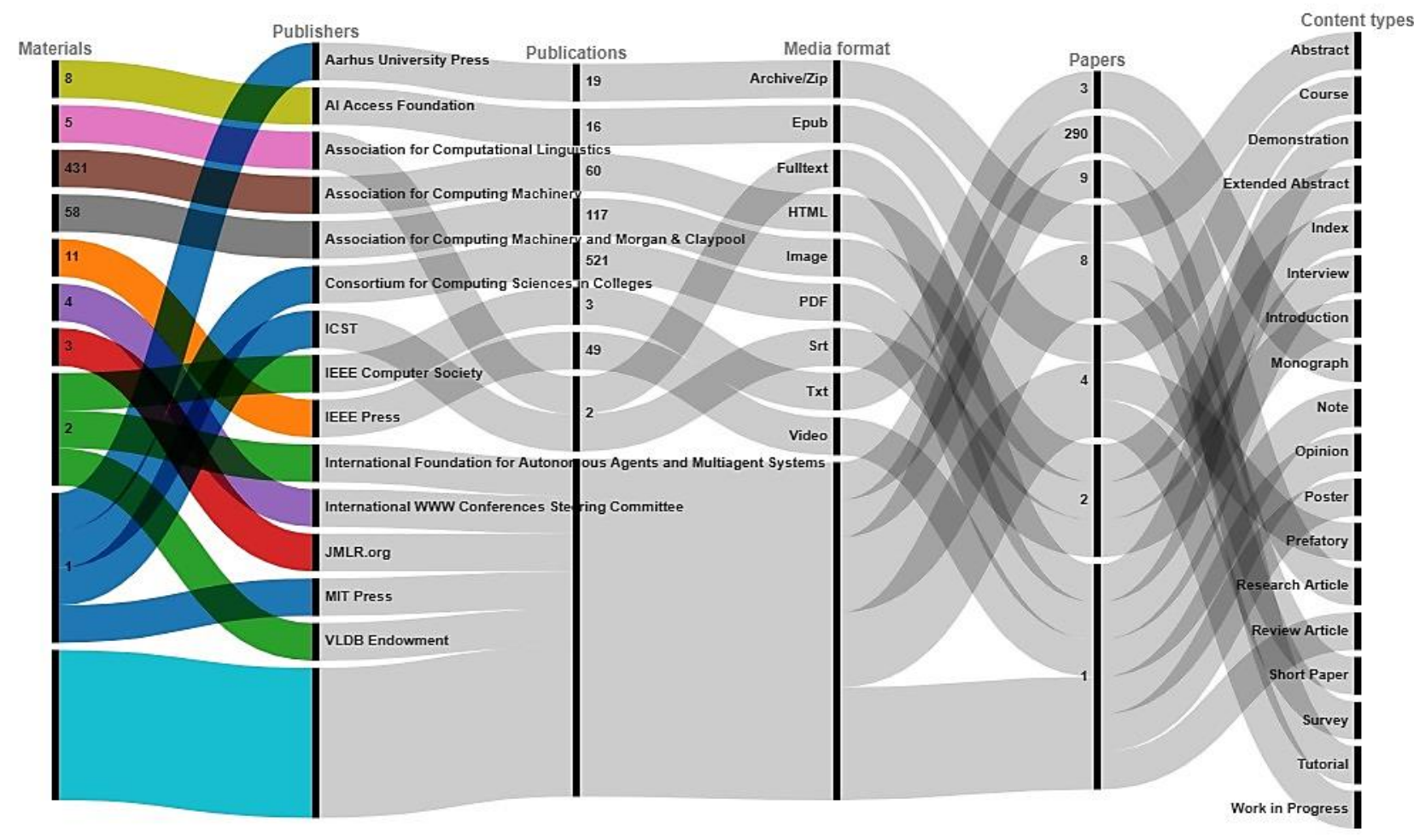

Figure 4. Publishers, media format, content types with publications

The conferences locations with total of materials published in the IEEE library is demonstrated in figure 5 .

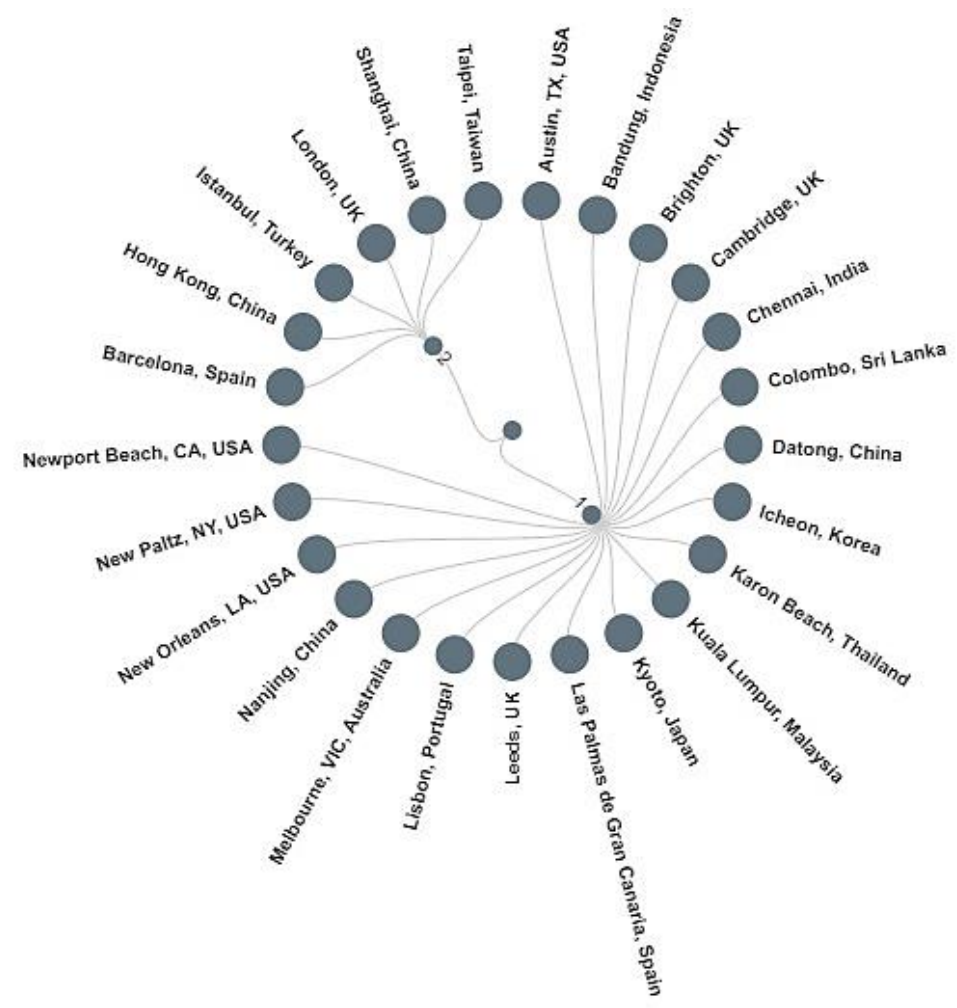


Figure 5. Conferences locations with materials published The publication topics in the same library are given in figure 6 .

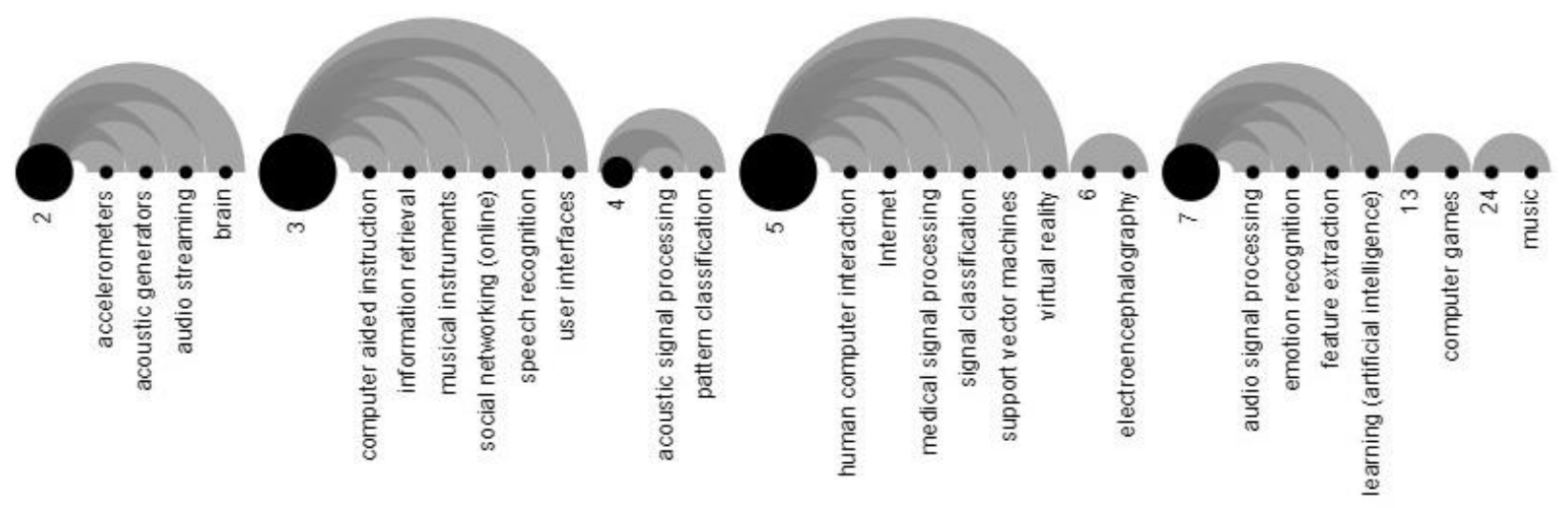

Figure 6. Publication topics with a number of papers

The article type in this library is given in figure 7.

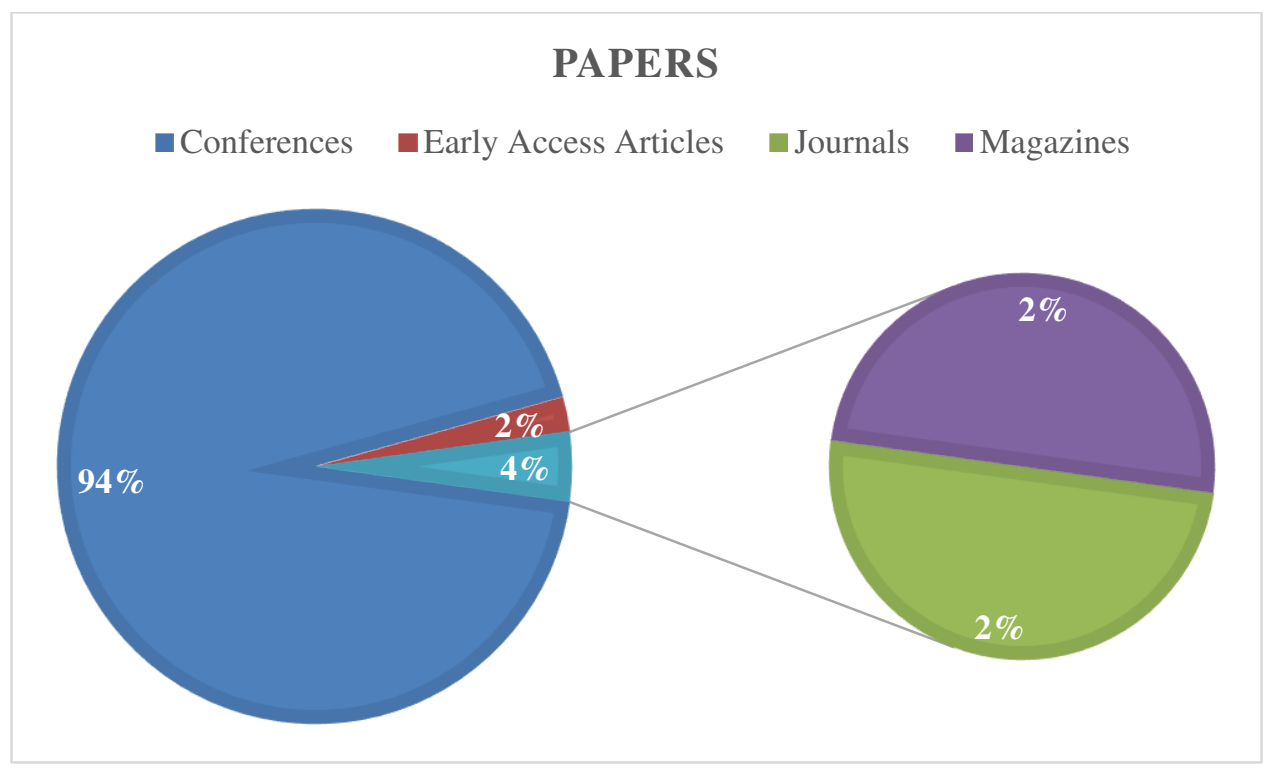

Figure 7. Article types with publications

The countries, journals, and research papers published in the MDPI library are given in figure 8 . 


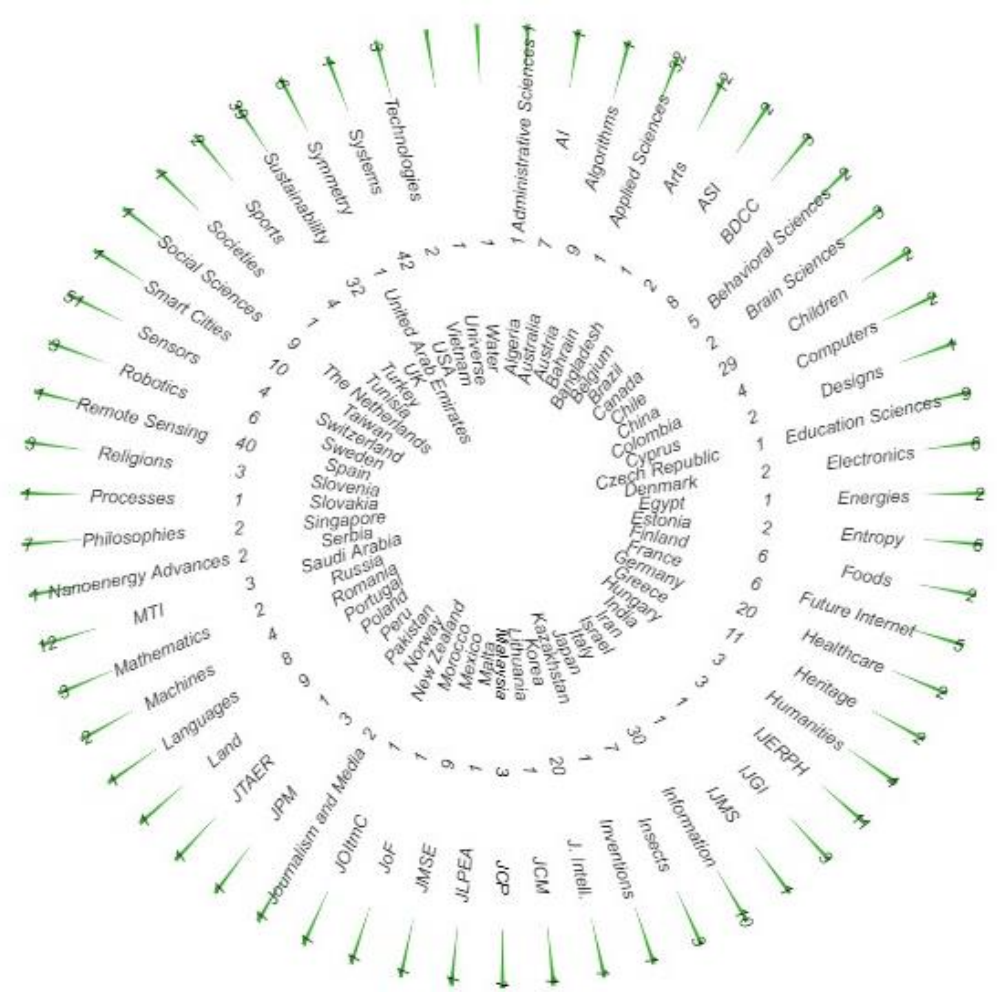

Figure 8. Countries, journals, and total publications

The types of articles in the same library are demonstrated in figure 9.

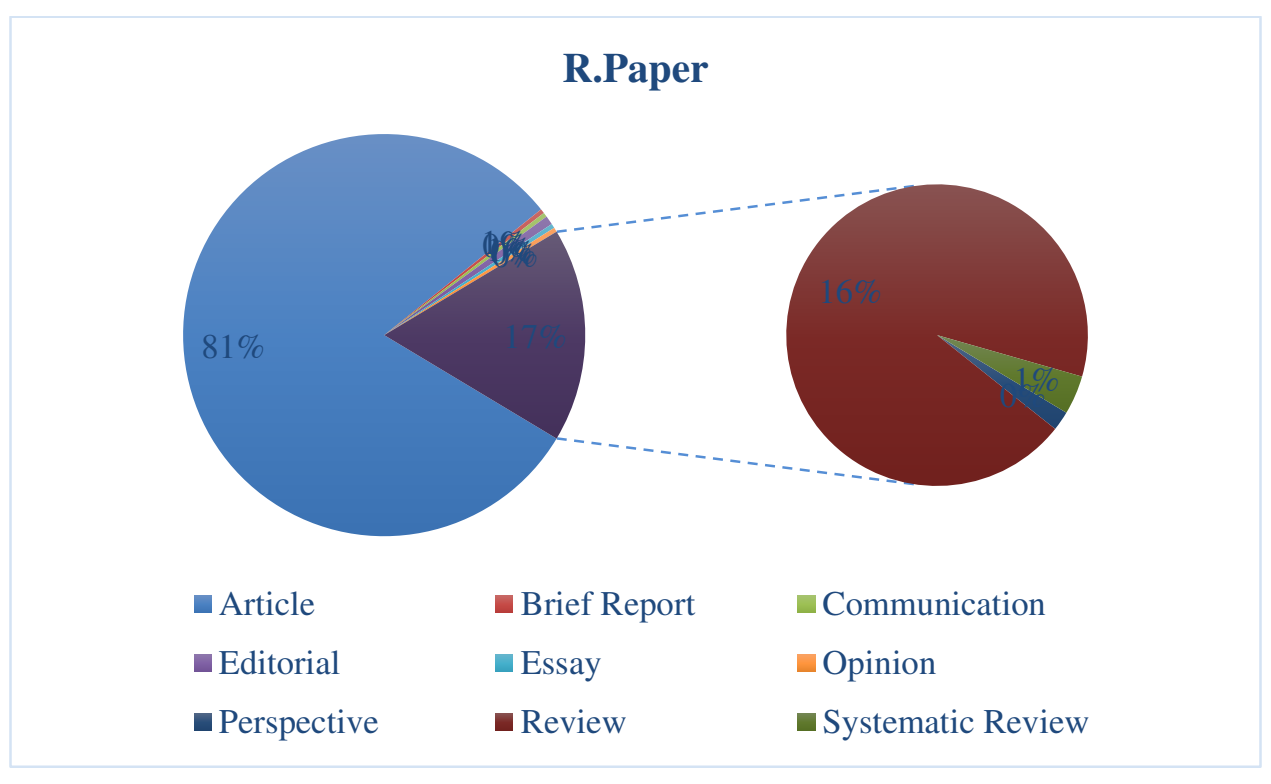

Figure 9. Type of articles with publications

The subject areas with research papers published in the same library is mentioned in figure 10. 


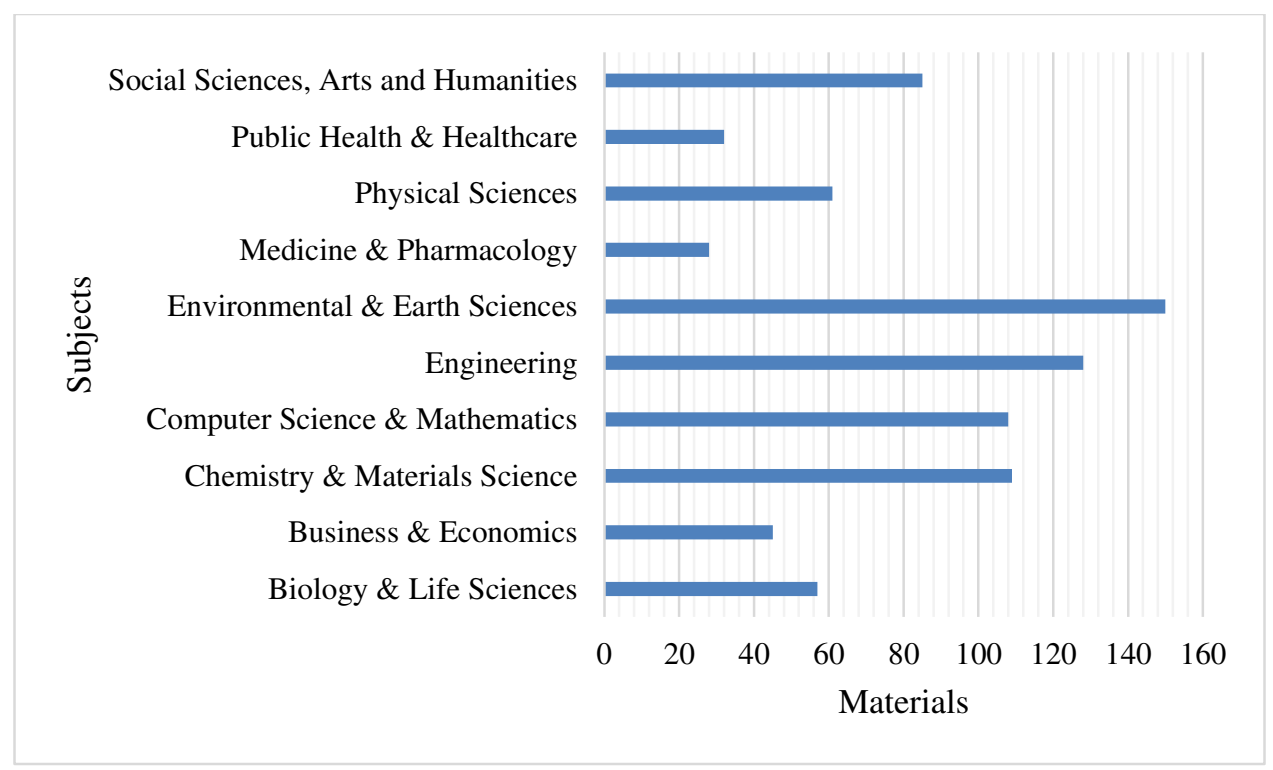

Figure 10. Subject area with publications

\section{Conclusion}

As one of the humans' exciting and precious creations, music can now be generated and composed by intelligent and intelligent machines. With the deployment of artificial intelligence-based intelligent algorithms, the devices can produce high-quality and pleasant music without any interaction of human beings. These intelligent techniques are capable of recommending music to the listener according to the situation and mood. Digitization has improved the profit generated by the music industry, and it is effortless for the listener to search for the music of its own choice. Sounds is playing a very efficient and beneficial role on every platform like games. With better sound management, game designers can design and develop a very interactive and persuasive game. The type and style of sound used in a game affect the player's performance along with the interactivity of that game. For the increasing addiction of gamers, the sound used in the game must be dynamic and according to the atmosphere of the game. Audio in the game is an essential factor and is able to provide the gamer with information about different scenarios and sequences. AI-based innovative and intelligent methodologies should be applied to create practical and intellectual tools and devices to compose dynamic and attractive audio in the games. With the integration of AI and sound engines, the game professionals will generate high-quality and user-centric audio for the better and efficient designing of a video game. The present study has considered a detailed indication of the literature accessible in the area of research. The study has revealed literature analysis from various viewpoints, which will suggest researchers devise novel solutions in the field.

\section{Conflict of interest}

The authors have no conflict of interest 


\section{Ethical approval}

My paper does not deal with any ethical problems.

\section{Funding details}

The paper did not receive any financial support.

\section{Informed Consent}

We declare that all authors have informed Consent.

\section{References}

[1] R. L. De Mantaras and J. L. Arcos, "AI and music: From composition to expressive performance," AI magazine, vol. 23, no. 3, pp. 43-43, 2002.

[2] C. Roads, "Research in music and artificial intelligence," ACM Computing Surveys, vol. 17, no. 2, pp. 163-190, 1985.

[3] E. Frid, C. Gomes, and Z. Jin, "Music creation by example," in Proceedings of the 2020 CHI Conference on Human Factors in Computing Systems, 2020, pp. 1-13.

[4] B. L. Sturm, M. Iglesias, O. Ben-Tal, M. Miron, and E. Gómez, "Artificial intelligence and music: open questions of copyright law and engineering praxis," in Arts, 2019, vol. 8, no. 3, p. 115: Multidisciplinary Digital Publishing Institute.

[5] O. Lopez-Rincon, O. Starostenko, and G. Ayala-San Martín, "Algoritmic music composition based on artificial intelligence: A survey," in 2018 International Conference on Electronics, Communications and Computers (CONIELECOMP), 2018, pp. 187-193: IEEE.

[6] R. Louie, A. Coenen, C. Z. Huang, M. Terry, and C. J. Cai, "Novice-AI music co-creation via AIsteering tools for deep generative models," in Proceedings of the 2020 CHI Conference on Human Factors in Computing Systems, 2020, pp. 1-13.

[7] X. Tan and X. Li, "A Tutorial on AI Music Composition," in Proceedings of the 29th ACM International Conference on Multimedia, 2021, pp. 5678-5680.

[8] Z. Qiu et al., "Mind Band: a crossmedia AI music composing platform," in Proceedings of the 27th ACM International Conference on Multimedia, 2019, pp. 2231-2233.

[9] H. Zulić, "How AI can change/improve/influence music composition, performance and education: three case studies," INSAM Journal of Contemporary Music, ArtTechnology, vol. 1, no. 2, pp. 100-114, 2019.

[10] A. Camurri, "On the role of artificial intelligence in music research," Journal of New Music Research, vol. 19, no. 2-3, pp. 219-248, 1990. 
[11] S. Malgaonkar, Y. B. Nag, R. Devadiga, and T. Hirave, "An AI based intelligent music composing algorithm: Concord," in 2013 International Conference on Advances in Technology and Engineering (ICATE), 2013, pp. 1-6: IEEE.

[12] M. D. Pandian, "Sleep pattern analysis and improvement using artificial intelligence and music therapy," Journal of Artificial Intelligence, vol. 1, no. 02, pp. 54-62, 2019.

[13] R. B. Dannenberg, "Artificial intelligence, machine learning, and music understanding," in Proceedings of the 2000 Brazilian Symposium on Computer Music: Arquivos do Simpsio Brasileiro de Computao Musical (SBCM), 2000.

[14] R. B. Dannenberg, "Music representation issues, techniques, and systems," Computer Music Journal, vol. 17, no. 3, pp. 20-30, 1993.

[15] R. Fox and A. Khan, "Artificial intelligence approaches to music composition," in Proceedings on the International Conference on Artificial Intelligence (ICAI), 2013, p. 1: The Steering Committee of The World Congress in Computer Science, Computer ....

[16] L. Kumar, P. Goyal, and R. Kumar, "Creativity in machines: Music composition using artificial intelligence," Asian Journal For Convergence In Technology ISSN--, vol. 6, no. 2, pp. 36-40, 2020.

[17] S. Neeman, "Arts, computers and artificial intelligence," in Technology-Based Re-Engineering Engineering Education Proceedings of Frontiers in Education FIE'96 26th Annual Conference, 1996, vol. 3, pp. 1397-1401: IEEE.

[18] J. A. Lupker and W. J. Turkel, "Music Theory, the Missing Link Between Music-Related Big Data and Artificial Intelligence," DHQ: Digital Humanities Quarterly, vol. 15, no. 1, 2021.

[19] N. Kazi and S. Bhatia, "Various artificial intelligence techniques for automated melody generation," International Journal of Engineering Research, vol. 2, pp. 1646-1652, 2013.

[20] C. Guéret, N. Monmarché, and M. Slimane, "Ants can play music," in International Workshop on Ant Colony Optimization and Swarm Intelligence, 2004, pp. 310-317: Springer.

[21] P. Peerdeman, "Sound and music in games," Amsterdam: VrijeUniversiteit, pp. 2-3, 2010.

[22] K. Collins, "An introduction to procedural music in video games," Contemporary Music Review, vol. 28, no. 1, pp. 5-15, 2009.

[23] S. B. Linek, B. Marte, and D. Albert, "Background music in educational games: Motivational appeal and cognitive impact," International Journal of Game-Based Learning, vol. 1, no. 3, pp. 53-64, 2011.

[24] C. Plut and P. Pasquier, "Music Matters: An empirical study on the effects of adaptive music on experienced and perceived player affect," in 2019 IEEE Conference on Games (CoG), 2019, pp. 1-8: IEEE. 
[25] C. Plut and P. Pasquier, "Generative music in video games: State of the art, challenges, and prospects," Entertainment Computing, vol. 33, p. 100337, 2020.

[26] H. O. K. Ahmed, "Flipped learning as a new educational paradigm: An analytical critical study," European Scientific Journal, vol. 12, no. 10, 2016.

[27] A. Gungormusler, N. Paterson-Paulberg, and M. Haahr, "barelymusician: An adaptive music engine for video games," in Audio engineering society conference: 56th international conference: audio for games, 2015: Audio Engineering Society.

[28] M. Grimshaw, S.-L. Tan, and S. D. Lipscomb, "Playing with sound: The role of music and sound effects in gaming," American Psychological Association, 2013.

[29] S.-L. Tan, J. Baxa, and M. P. Spackman, "Effects of built-in audio versus unrelated background music on performance in an adventure role-playing game," International Journal of Gaming Computer-Mediated Simulations, vol. 2, no. 3, pp. 1-23, 2010.

[30] C. I. Karageorghis, M. Bigliassi, K. Tayara, D.-L. Priest, and J. M. Bird, "A grounded theory of music use in the psychological preparation of academy soccer players," Sport, Exercise, Performance Psychology, vol. 7, no. 2, p. 109, 2018.

[31] M. Avdeeff, "Artificial intelligence \& popular music: SKYGGE, flow machines, and the audio uncanny valley," in Arts, 2019, vol. 8, no. 4, p. 130: Multidisciplinary Digital Publishing Institute.

[32] F. Waldner, "Cross-industry innovation: The transfer of a service-based business model from the video game industry to the music industry," in 2011 International Conference on Emerging Intelligent Data and Web Technologies, 2011, pp. 143-147: IEEE.

[33] N. Scott, "Music to middleware: The growing challenges of the game music composer," in Proceedings of the 2014 Conference on Interactive Entertainment, 2014, pp. 1-3.

[34] H. C. Rietveld et al., "Hear The Music, Play The Game. Music And Game Design: Interplays And Perspectives," in game, 2017, vol. 1, no. 6: GAME: Games, Arts, Media, Entertainment. 1 (6).

[35] D. Arditi, "Music Everywhere: Setting a Digital Music Trap," Critical Sociology, vol. 45, no. 4-5, pp. 617-630, 2019.

[36] C. Sitonio and A. Nucciarelli, "The impact of blockchain on the music industry," presented at the 29th European Regional ITS Conference, Trento 2018, 2018.

[37] M. Đ. Võ, T. T. Lê, H. Q. Nguyễn, V. T. V. Trương, and T. V. Đỗ, "Music Arena Game," FUG HCM, 2015.

[38] D. L. Newcomb, The fundamentals of the video game music genre. James Madison University, 2012. 
[39] D. Plans and D. Morelli, "Experience-driven procedural music generation for games," IEEE Transactions on Computational Intelligence AI in Games, vol. 4, no. 3, pp. 192-198, 2012.

[40] A. Aska, Introduction to the study of video game music. Lulu. com, 2017.

[41] A. Ghildiyal and S. Sharma, "Music Genre Classification Using Data Filtering Algorithm: An Artificial Intelligence Approach," in 2021 Third International Conference on Inventive Research in Computing Applications (ICIRCA), 2021, pp. 922-926: IEEE.

[42] Y. Hou, "Discussion on Practice and Promotion Strategy of College Music Education Informatization Based on Artificial Intelligence," in 2020 International Conference on Computers, Information Processing and Advanced Education (CIPAE), 2020, pp. 114-116: IEEE.

[43] S. Yuan, "Application and Study of Musical Artificial Intelligence in Music Education Field," in Journal of Physics: Conference Series, 2020, vol. 1533, no. 3, p. 032033: IOP Publishing.

[44] J. Zhang and J. Wan, "A Summary of the Application of Artificial Intelligence in Music Education," in International Conference on Education, Economics and Information Management (ICEEIM 2019), 2020, pp. 42-44: Atlantis Press.

[45] F. Yang, "Artificial Intelligence in Music Education," in 2020 International Conference on Robots \& Intelligent System (ICRIS), 2020, pp. 483-484: IEEE.

[46] S. Nicholls, S. Cunningham, and R. Picking, "Collaborative artificial intelligence in music production," in Proceedings of the Audio Mostly 2018 on Sound in Immersion and Emotion, 2018, pp. 1-4.

[47] T. J. B. D. Birtchnell and Society, "Listening without ears: Artificial intelligence in audio mastering," Big Data \& Society, vol. 5, no. 2, p. 2053951718808553, 2018.

[48] C.-C. Stere and Ş. Trăuşan-Matu, "Generation of musical accompaniment for a poem, using artificial intelligence techniques," International Journal of User-System Interaction, vol. 10, no. 3, pp. 250-270, 2017.

[49] X. Zhang and D. Yang, "Research on Music Assisted Teaching System Based on Artificial Intelligence Technology," in Journal of Physics: Conference Series, 2021, vol. 1852, no. 2, p. 022032: IOP Publishing.

[50] S. Hébert, R. Béland, O. Dionne-Fournelle, M. Crête, and S. J. Lupien, "Physiological stress response to video-game playing: the contribution of built-in music," Life sciences, vol. 76, no. 20, pp. 2371-2380, 2005.

[51] J.-H. Lee, "A Study of the Changes of Game Music," Journal of Korea Game Society, vol. 12, no. 1, pp. 103-111, 2012.

[52] T. Li and M. Ogihara, "Detecting emotion in music," International Conference on Music Information Retrieval, 2003. 
[53] M. Müller, V. Konz, W. Bogler, and V. Arifi-Müller, "Saarland music data (SMD)," in Proceedings of the international society for music information retrieval conference (ISMIR): late breaking session, 2011.

[54] R. B. Shapiro, A. Kelly, M. Ahrens, B. Johnson, H. Politi, and R. Fiebrink, "Tangible distributed computer music for youth," Computer Music Journal, vol. 41, no. 2, pp. 52-68, 2017.

[55] I. B. Gorbunova and A. A. Govorova, "Music Computer Technologies as a Means of Teaching the Musical Art for Visually-Impaired People," in Int'l Conference Proceedings, 2018, pp. 19-22.

[56] A. Pazos, A. S. Del Riego, J. Dorado, and J. R. Caldalda, "Genetic music compositor," in Proceedings of the 1999 Congress on Evolutionary Computation-CEC99 (Cat. No. 99TH8406), 1999, vol. 2, pp. 885-890: IEEE.

[57] A. Elowsson and A. Friberg, "Algorithmic composition of popular music," in the 12th International Conference on Music Perception and Cognition and the 8th Triennial Conference of the European Society for the Cognitive Sciences of Music, 2012, pp. 276-285.

[58] A. A. Gunawan and D. Suhartono, "Music recommender system based on genre using convolutional recurrent neural networks," Procedia Computer Science, vol. 157, pp. 99-109, 2019.

[59] J.-H. Su, W.-Y. Chang, and V. S. Tseng, "Personalized music recommendation by mining social media tags," Procedia Computer Science, vol. 22, pp. 303-312, 2013.

[60] M. Lee, H. Choi, D. Cho, and H. Lee, "Cannibalizing or complementing?. The impact of online streaming services on music record sales," Procedia Computer Science, vol. 91, pp. 662-671, 2016.

[61] V. Arutyunov and A. Averkin, "Genetic algorithms for music variation on genom platform," Procedia computer science, vol. 120, pp. 317-324, 2017.

[62] A. Forsberg, M. Dieterich, and R. Zeleznik, "The music notepad," in Proceedings of the 11th annual ACM symposium on User interface software and technology, 1998, pp. 203-210.

[63] S. Dixon, "On the computer recognition of solo piano music," in Proceedings of Australasian computer music conference, 2000, pp. 31-37.

[64] A. Brown and T. Kerr, "Adaptive music techniques," in Proceedings of Improvise: the Australasian Computer Music Conference 2009, 2009, pp. 26-31: Australasian Computer Music Association.

[65] K. Monteith, T. R. Martinez, and D. Ventura, "Automatic Generation of Music for Inducing Emotive Response," in ICCC, 2010, pp. 140-149: Citeseer.

[66] D. Gärdenfors, "Designing sound-based computer games," Digital Creativity, vol. 14, no. 2, pp. 111-114, 2003. 
[67] I. Ekman, "Meaningful noise: Understanding sound effects in computer games," Proc. Digital Arts Cultures, vol. 17, 2005.

[68] J. R. Parker and J. Heerema, "Audio interaction in computer mediated games," International Journal of Computer Games Technology, vol. 2008, 2008.

[69] G. Roux-Girard, "Listening to fear: A study of sound in horror computer games," in Game sound technology and player interaction: Concepts and developments: IGI Global, 2011, pp. 192-212.

[70] K. Jørgensen, Left in the dark: playing computer games with the sound turned off. Ashgate, 2008.

[71] P. Ng and K. Nesbitt, "Informative sound design in video games," in Proceedings of The 9th Australasian Conference on Interactive Entertainment: Matters of Life and Death, 2013, pp. 1-9.

[72] N. Böttcher, "Current problems and future possibilities of procedural audio in computer games," Journal of Gaming Virtual Worlds, vol. 5, no. 3, pp. 215-234, 2013.

[73] K. Rogers, "Exploring the Role of Audio in Games," in Extended Abstracts Publication of the Annual Symposium on Computer-Human Interaction in Play, 2017, pp. 727-731. 